\title{
Covid-19: Doctors and nurses demand better PPE for wider range of procedures
}

\section{Jacqui Wise}

Healthcare workers are calling on the government to ensure that higher grade personal protective equipment (PPE) is mandatory for a range of procedures, such as fitting nasogastric tubes, because of the risk of aerosol transmission of SARS CoV-2.

Current guidance from Public Health England is for hospital staff to wear surgical masks in most areas, with filtering face piece class $3\left(\mathrm{FFP}_{3}\right)$ respirator masks required only in intensive care or when certain procedures are carried out that are known to generate aerosols.

However, Public Health England's current categorisation of some procedures as non-aerosol-generating is based on outdated evidence and leaves staff at increased risk of covid-19 infection, say campaigners.

Fresh Air NHS, a group of frontline healthcare workers, has written an open letter to UK political leaders calling for the UK and devolved governments to recognise the importance of airborne transmission of SARS CoV-2 and ensure that measures are in place to protect staff and patients. ${ }^{1}$

The letter, signed by a thousand health professionals, calls for immediate access to FFP3 masks for all staff working with patients with confirmed or suspected covid-19 and for a review of national PPE guidance. They are also calling for ventilation in hospitals to be improved.

\section{Underestimated}

The AGP Alliance, a coalition of organisations including the British Association for Parenteral and Enteral Nutrition, the National Nurse Nutrition Group, the British Association of Stroke Physicians, and the British Society of Gastroenterology, has been campaigning since April for an urgent review of the definition of aerosol generating procedures. ${ }^{2}$ They have written to the health secretary, the prime minister, and the four chief medical officers but say that they have not had a meaningful response.

The alliance says that some procedures such as the fitting of nasogastric tubes for feeding or drainage, swallowing assessment, chest physiotherapy, and cardiopulmonary resuscitation require close physical contact within one metre of a patient for prolonged periods and frequently induce coughing or sneezing in the patient. They say that doctors, nurses, and other healthcare workers carrying out these procedures should be issued with $\mathrm{FFP}_{3}$ respirators, face shields, and fluid repellent gowns.

Barry Jones, a retired gastroenterologist and chair of the AGP Alliance, told The BMJ, "The evidence on nasogastric tube insertion is based on studies from the SARS 2003 epidemic, but it was described as unfit for clinical decision making in the Health Protection Scotland review on which Public Health England's guidance is based.

“The possibility that some procedures currently not regarded as aerosol generating procedures may be contributing to the transmission of covid-19 in hospitals cannot be excluded, even if it cannot be proved. These patients are producing aerosols, and the risks must be minimised. Present PPE guidance is clearly not working."

In July experts warned that airborne transmission was being underestimated. ${ }^{3}$ In September the US Centers for Disease Control and Prevention (CDC) provoked controversy when it first published information saying that covid-19 could be spread through aerosols and then removed the information. ${ }^{4}$ The CDC now says growing evidence shows that covid-19 infection can occur from airborne exposure to the virus under certain circumstances but that it is much more common through close contact with an infected person. ${ }^{5}$

\section{Inaction}

In the UK an independent panel on high risk aerosol generating procedures was commissioned by the Department of Health and Social Care in May to provide advice to the chief medical officers. It first met in July but has yet to publish a report.

“The situation is a scandal," said Jones. "Many are catching covid-19 in hospitals, and some are dying, as a result of this inaction. It's the air we share that's killing us."

A few trusts, such as Southampton, Cambridge, Plymouth, and Exeter, are believed to be taking a more pragmatic approach to Public Health England's guidance and have decided to equip all staff with $\mathrm{FFP}_{3}$ masks if they face patients with confirmed or suspected covid-19.

Donna Kinnair, chief executive of the Royal College of Nursing, called for urgent reassurance from government ministers that PPE sufficiently protects healthcare workers, particularly in light of the new variant of covid-19. "Without delay, they must state whether existing PPE guidance is adequate for the new variant," she said. "While more research is carried out, we ask for the precautionary principle to be applied and for staff to be given a higher level of PPE if working with suspected or confirmed cases."

A Department of Health and Social Care spokesperson commented, "The safety of NHS and social care staff has always been our top priority, and we continue to work tirelessly to deliver PPE to protect those on the front line. 
"UK guidance on the safest levels of PPE is written by experts and agreed by all four chief medical officers. The guidance is kept under constant review based on the latest evidence and data."

Correction: On 6 January 2021 we amended the first sentence in paragraph 7 to include "the fitting of nasogastric tubes for feeding or drainage" rather than just "the fitting of nasogastric tubes for drainage".

1 Fresh Air NHS. Improve ventilation of care settings \& upgrade respiratory personal protective equipment-open letter. Jan 2021. https://docs.google.com/forms/d/e/1FAlpQLSejgqHBTsCjfOG3BdZRHsBzx4cMxZEEnarozhztDo4tdc4zdQ/viewform?gxids=7628.

2 AGP Alliance. Position statement on AGPs/PPE September 2020. Updated Oct 2020. https://www.bapen.org.uk/pdfs/covid-19/agp-alliance-position-paper.pdf.

3 Dyer 0. Covid-19: Airborne transmission is being underestimated, warn experts. BMJ 2020;370:m2720. doi: 10.1136/bmj.m2720 pmid: 32636182

4 Tanne JH. Covid-19: CDC publishes then withdraws information on aerosol transmission. BMJ 2020;370:m3739. doi: 10.1136/bmj.m3739 pmid: 32973037

5 Centers for Disease Control and Prevention. Scientific brief: SARS-CoV-2 and potential airborne transmission. Updated 50ct 2020. https://www.cdc.gov/coronavirus/2019-ncov/more/scientificbrief-sars-cov-2.html.

This article is made freely available for use in accordance with BMJ's website terms and conditions for the duration of the covid-19 pandemic or until otherwise determined by BMJ. You may use, download and print the article for any lawful, non-commercial purpose (including text and data mining) provided that all copyright notices and trade marks are retained. 